International Archives of the Photogrammetry, Remote Sensing and Spatial Information Sciences, Volume XXXIX-B5, 2012 XXII ISPRS Congress, 25 August - 01 September 2012, Melbourne, Australia

\title{
IMAGING A SUSTAINABLE FUTURE IN 3D
}

\author{
W.Schuhr ${ }^{\mathrm{a}, *}$, J.D. Lee ${ }^{\mathrm{b}}$, E. Kanngieser ${ }^{\mathrm{c}}$ \\ ${ }^{a}$ University of Applied Sciences Magdeburg, Germany - Schuhr3D@hotmail.com \\ ${ }^{b}$ Kumoh National University of Technology (kit), Gumi, Republic of Korea - jdlee@kumoh.ac.kr \\ cHafenCity University Hamburg, Germany - erich.kanngieser@hcu-hamburg.de
}

Working Group, Theme or Special Session: V/2: Cultural Heritage Data Acquisition and Processing

KEY WORDS: Cultural Heritage, History, Internet/Web, Human Settlement, Technology

\section{ABSTRACT:}

It is the intention of this paper, to contribute to a sustainable future by providing objective object information based on 3D photography as well as promoting 3D photography not only for scientists, but also for amateurs. Due to the presentation of this article by CIPA Task Group 3 on "3D Photographs in Cultural Heritage”, the presented samples are masterpieces of historic as well as of current 3D photography concentrating on cultural heritage.

In addition to a report on exemplarily access to international archives of 3D photographs, samples for new 3D photographs taken with modern 3D cameras, as well as by means of a ground based high resolution XLITE staff camera and also 3D photographs taken from a captive balloon and the use of civil drone platforms are dealt with.

To advise on optimum suited 3D methodology, as well as to catch new trends in 3D, an updated synoptic overview of the 3D visualization technology, even claiming completeness, has been carried out as a result of a systematic survey.

In this respect, e.g., today's lasered crystals might be “early bird” products in 3D, which, due to lack in resolution, contrast and color, remember to the stage of the invention of photography.

\section{INTRODUCTION}

The ISPRS 2012 congress in Melbourne runs under the motto "IMAGING A SUSTAINABLE FUTURE". A sustainable future requires a smart and fair resources management, aiming at poverty reduction and strongly avoiding any type of wasting, like, e.g. living at nature's expense and/or willful destruction of

cultural monuments etc.. Doubtless 3D photography, beside others is an important basic documentation tool to judge on the success of measures for a sustainable future by, e.g., comparing historic sources, hence international historic 3D photographs with current 3D photographs and/or even with photo-realistic planning of a sustainable future in $3 \mathrm{D}$.

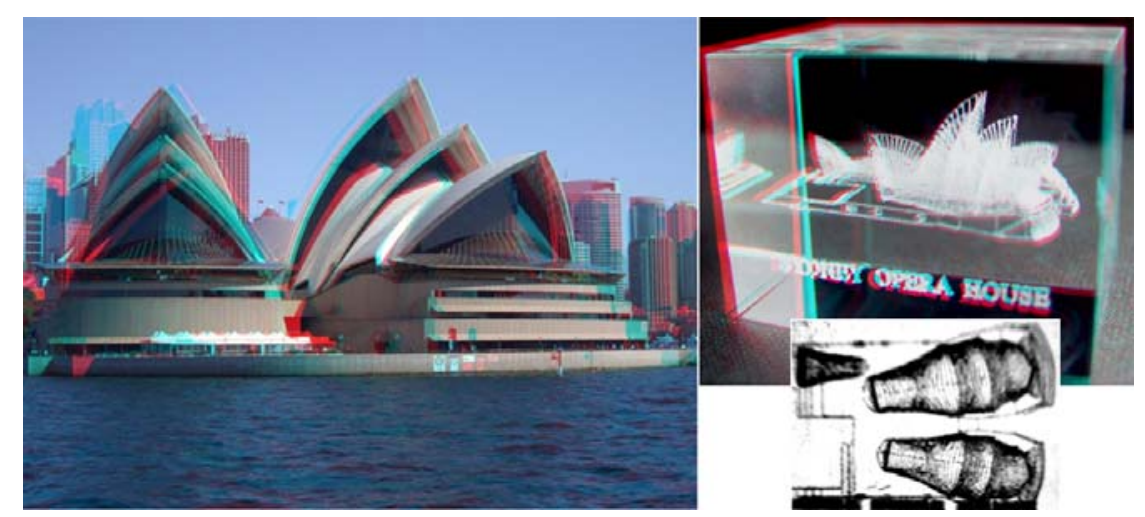

Figure 1. As a homage in 3D to the $23^{\text {rd }}$ ISPRS Congress in Melbourne color anaglyphs of the famous Sydney Opera (left) are presented in comparison with an "early bird” lasered crystal, including the plan projection (right; courtesy R.Titze of LOOXIS, Hannover; photographs by the authors, use color anaglyph glasses!)

\section{OBJECTIVES}

2.1 It is the intention of this paper, to contribute to a sustainable future, providing objective object information based on 3D photography as well as

\subsection{Promoting 3D photography}

for scientists, as well as for amateurs.
2.3 Due to the presentation of this article by CIPA task group 3 on "3D Photographs in Cultural Heritage", the presented samples are masterpieces of historic as well as of current 3D photography, concentrating on cultural heritage.

\subsection{Access to international archives}

of 3D photographs at least exemplarily will be dealt with.

2.5 To advise on optimum suited 3D methodology 
as well as to catch new trends in 3D, an updated synoptical overview, even claiming completeness, shall be carried out as a result of a systematic survey of the $3 \mathrm{D}$ visualization technology.

\section{METHODS}

\subsection{Applying and improving the processing to present} masterpieces of existing 3D photography.

\subsection{To evaluate international archives of existing analog and digital 3D photography}

\subsection{Experimental exposing new 3D photography,} including

- the use of 3D cameras, like, e.g., the Fuji Fine Pix Real 3D and a

- ground based high resolution XLITE staff 3D photography from about $13 \mathrm{~m}$ height, as well as

- 3D photography taken from a captive balloon and - by means of civil drone platforms.

\subsection{A systematic survey for 3D visualization methods,} seeking completeness

\section{RESULTS}

\subsection{The following 2 samples of existing auto stereoscopic}

black and white masterpieces, presented as color anaglyphs are samples for outstanding historic heritage 3D photography:

- The historic 3D image of the Cologne Cathedral (Germany), see Figure 2 (left) and

- the photographic masterpiece in 3D (approx. 1910) of the Leaning Tower of Pisa (Italy), see Figure 3 (right) represent approximately 350.000 3D photographs of the Keystone-Mast collection, see Figure 4.
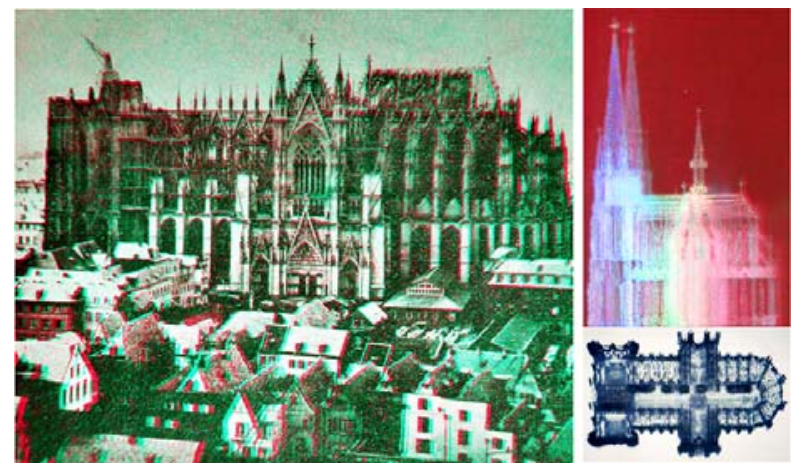

Figure 2. The eldest stereo view (approx. from 1856) of the famous Cologne Cathedral (Germany), even showing remaining cranes of the middle age and the towers are still incomplete, presented in color anaglyphs, in comparison with a modern lasered crystal showing the Cologne Cathedral in 3D and an oblique situation plan of the crystal (photographs by the authors, use anaglyph glasses!)

\subsection{These masterpieces represent huge archives}

of international 3D photography (see Figure 2 and 3), like, e.g., the famous Keystone-Mast collection of the California Museum of Photography (CMP, see Figure 4). Therefore not only acquiring a list, showing such archives, is highly recommended, but also a detailed documentation of estimated at least some million international historic 3D photographs in a global GIS system, like on google earth is overdue.
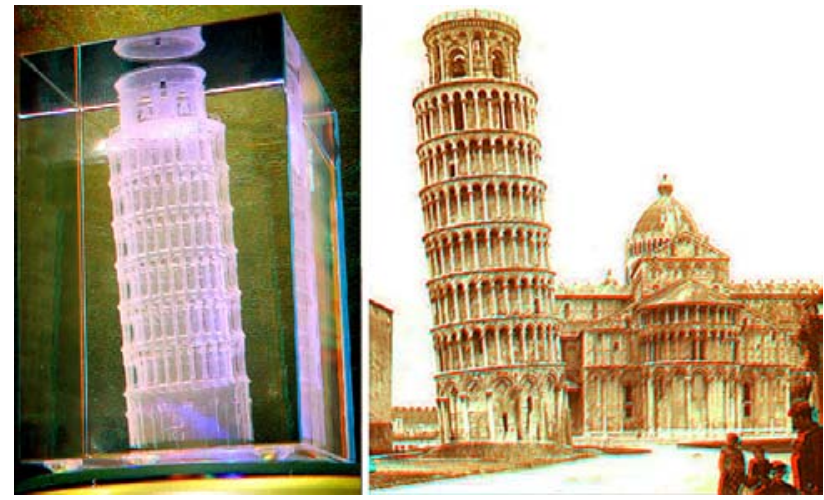

Figure 3. Color anaglyphs of an "early bird” lasered crystal of the famous Leaning Tower of Pisa (Italy) (left; courtesy R.Titze of LOOXIS, Hannover) in comparison with a historic 3D photography (photographs by W. Schuhr)

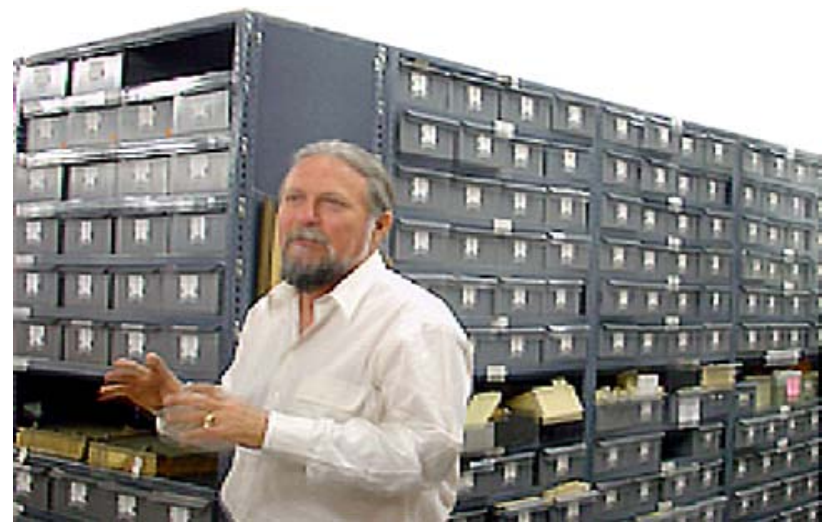

Figure 4. Inside the Keystone-Mast Collection, carrying approximately 350.000 original glass slides of international historic 3D photography: Steve Thomas, head of the CMP in Los Angeles (USA) in front of his "treasure in 3D" (processed photography: courtesy F.LeBlanc/GCI)

To derive optimum digitization rates for analog 3D photographs, in fig 5 is shown the "good" and even "high" (fuzzy) interpretation accuracy, respectively "mapping potential" of the original (3D-) photography in comparison with the decreasing results, as achieved from the interpretation of the same, but digitized photography. In this case the 3D photography showing $50 \mu \mathrm{m}$ pixel size results into an interpretation reliability very close to the original. Therefore as a $1^{\text {st }}$ result from this interpretations it can be stated, the minimum digitization rate for analog 3D photography at least should be approximately $500 \mathrm{dpi}$, which is equivalent to a pixel size of $50 \mu \mathrm{m}$. 


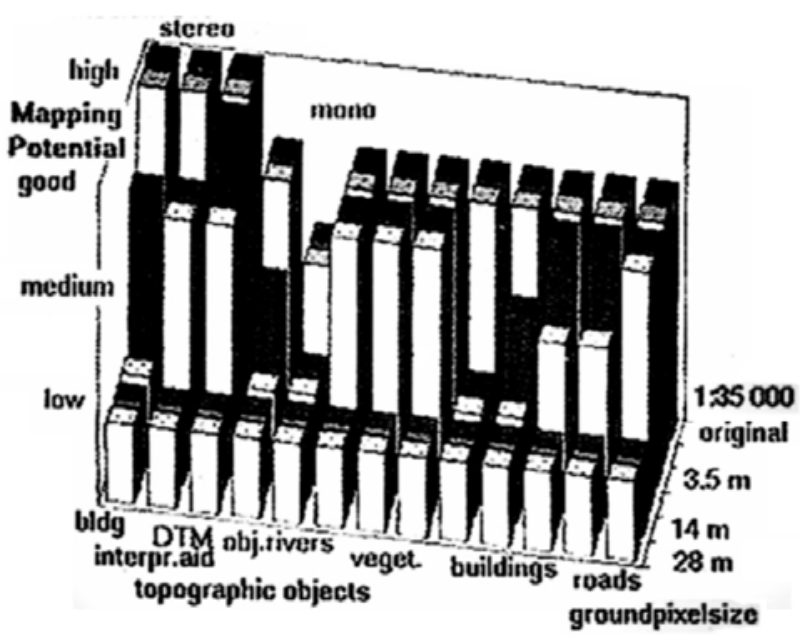

Figure 5. Comparison of the interpretation results of an original analog aerial 3D photography (scale 1:35 000) with the interpretation results obtained using the same stereo pair, but now digitized with 50, 100, 200, 400 and $800 \mu \mathrm{m}$ pixel size, equivalent to $1.8 \mathrm{~m}, 3.5 \mathrm{~m}, 7 \mathrm{~m}, 14 \mathrm{~m}$ and $28 \mathrm{~m}$ ground pixel size (EXCEL evaluation by W. Schuhr, based on interpretations by A. Elmhorst under the aegis of G. Konecny).

\subsection{Samples for new masterpieces of 3D photography}

The following 2 samples, obtained by the authors are typical new digital 3D photographs, using a conventional digital single lenses camera, as derived from a queue of about 5 images, showing guessed parallel optical axis directions and applying a professional 3D programme for processing color anaglyphs.
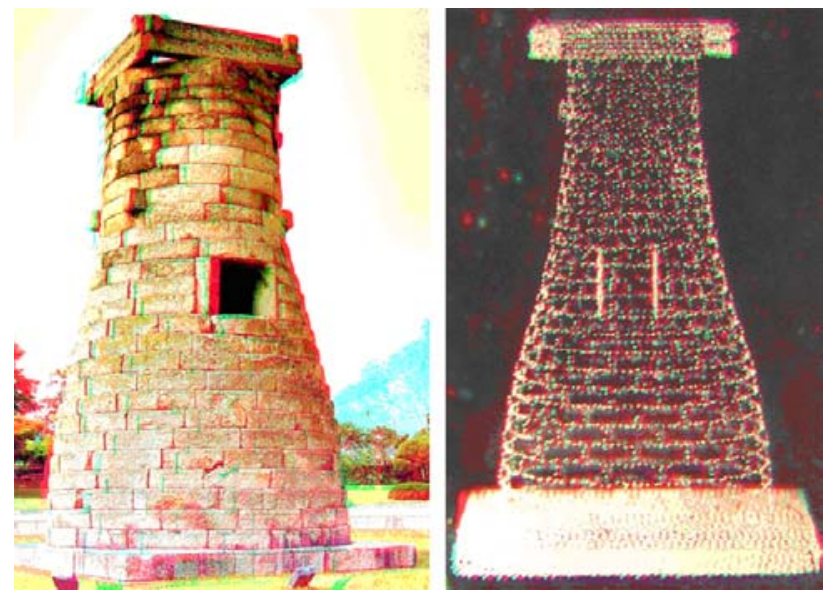

Figure 6. Color anaglyphs of a recent 3D photography of the ancient Cheomseongdae observatory in Gyeongju (Republic of Korea/South Korea) in comparison with a "zero generation" lasered crystal of the same object (photographs by the authors, use color anaglyph glasses!)

Figure 6 (left), possibly showing the world eldest observatory in South Korea, is a typical 3D photography taken (very fast) under "expedition constraints", while the sample in Figure 7 (left), showing the famous antique Egyptian bust of Nofretete represents 3D photography of outstanding objects of cultural heritage, exhibited in a museum.

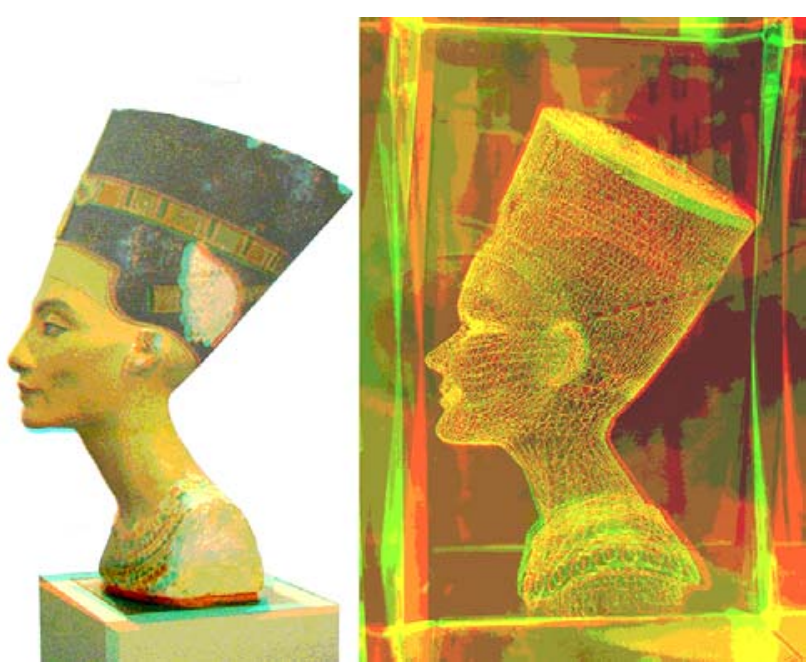

Figure 7. Detailed color anaglyphs of the famous bust of Nofretete from Tell el-Amarna (Egypt) (nowadays in Berlin, Germany) in comparison with an "early bird" lasered crystal, lacking resolution and radiometric significance.

The authors doubt, if there can be derived a universal formula, to calculate the (one and only) optimum base length, because the expectation criteria can individually differ from "insisting in a true 3D perception" until "requiring an extremely enhanced 3D perception”.

Therefore the authors highly recommend taking not just 2 stereo photographs but a queue of about 5 photographs with different base lengths, which allows a post processing according to different requirements.

For ground based high resolution (quasi ground truth) aerial photography the authors invented and applied very successful the XLITE digital telescope staff camera, in particular for 3D photographic documentation purposes of archaeological sites.

The system, showing full remote control is suited for a $13 \mathrm{~m}$ camera height, even under expedition constraints.

In Magdeburg this system has been supplemented by a captive helium balloon platform, suited for 3D photographs, including $360^{\circ}$ (3D-) panorama photography.

There seems to be an international trend to improve the applications of civil drone platforms in the next future. Even though drones already are operating with a "boomerang effect" based on GPS, it is liked to express a clear warning:

Due to their often underestimated danger caused by, e.g. losing control and/or power etc., drones should be operated by skilled and reliable stuff only, see Figure 9. 
International Archives of the Photogrammetry, Remote Sensing and Spatial Information Sciences, Volume XXXIX-B5, 2012 XXII ISPRS Congress, 25 August - 01 September 2012, Melbourne, Australia

4.4 As a result of a systematic survey of the 3D visualization Technology an updated synoptic overview, even claiming completeness (!) is presented in Table 1.

* VIRTUAL 3D VISUALIZATION PRINCIPLES:

1) 3D perception of in minimum 2 stereo mates, projected without contact for ortho, pseudo, for normal and/or cross 3D visualization: AUTO STEREOSCOPIC VIEW, MAGIC EYE/ RANDOM DOT, HEAD MOUNTED DISPLAY, STEREOSCOPES: LENS STEREOSCOPES and/or MIRROR STEREOSCOPES (e.g.: Wheatstone), vertical mirror: PIGEON; horizontal mirror: DOWN UNDER, PRISM STEREOSCOPES (horiz.stereo mates; (vertical: KMQ)), LENTICULAR LENSES (3D POSTCARDS), STRIP BARRIER

2) Stereo mates projected in contact, using alternate projection and/or different color via (COLOR-) ANAGLYPHS (compare Figures 1 to 3 and 6 to 8), DOLBY IN(TERFERENCE) FI(LTER)-TEC(HNOLOGY): multiplexing \& interference filter glasses, CROMA-DEPTHS (spectral color separation), POLARIZING FILTER TECHNIQUES, (Liquid Crystal) SHUTTER GLASSES, NuOptix (PULFRICH:3D movies \& CYBER SPACE)

3) 3D perception Techniques using VIRTUAL 3D MODELS: MIRRORS, 3D Rotating (FELIX 3D) or oscillating (BOLLOGRAPH) screen or (FELIX) 3D SOLID STATE SCREEN (a new 3D Computer screen generation?), HOLOGRAM Technologies

*REALITY \& REAL MODELS (see Figure 8) including lasered crystals (compare Figures 1,2,3,6,11 and 12)

Table 1. 3D visualization methods - the complete list - (status: ISPRS-Congress Melbourne 2012)

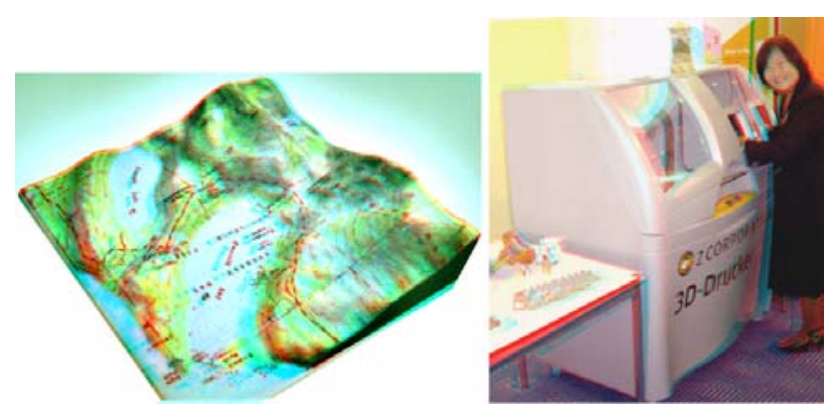

Figure 8. Of course real models also belong to the principals of 3D visualization, like here a terrain model, as carried out, by a 3D printer (courtesy Comp. KISTERS (Germany); 3D photographs by W.Schuhr, use color anaglyph glasses!)

\section{CONCLUSIONS}

\section{1 "Digging the treasure" of rare,}

unknown or even lost 3D photographs in the field of Cultural heritage should be a permanent task.

\subsection{In addition to the access to international archives} for 3D photography, the available 3D photography should appear in a global GIS-system, like on, e.g., google earth (see Figure 4).

\subsection{Currently 3D photography}

based on civil drone platforms promises a great future (see Figure 9).

\subsection{Though Table 1 is claiming completeness}

in stating 3D visualization Techniques, reports on missing 3D principles are very welcome.

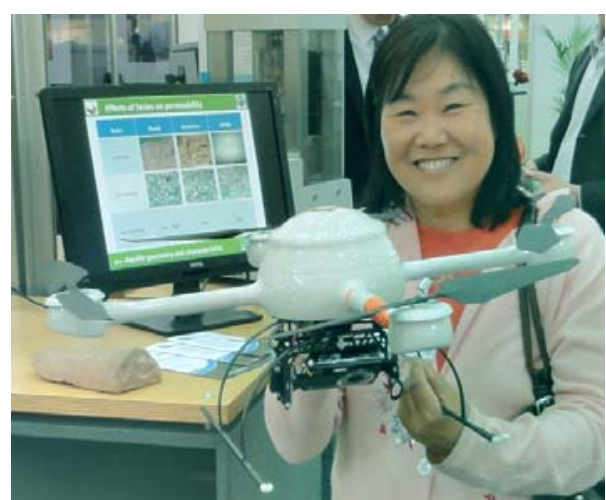

Figure 9. Ground steered civil drone platforms, carrying on board GPS and digital cameras, promise a great future (photography by W. Schuhr)..

\subsection{A consequent dealing with 3D Technology}

according to Table 1 can even lead to the very beginning of a new age of "real" 3D-PC-screens, in which "old fashioned" 2D-PC-screens at least partly might be replaced by new generation 3D-screens.

A first sample for this paradigm change from 2D into 3D PC screen technology is the FELIX solid state prototype.

Here the spatial visualization of 3D images already works without any glasses.

In this respect today's lasered crystals also might be "early bird" products in 3D, which, due to lack in resolution, contrast and color, appear somehow comparable to the stage of the invention of the photography by Niépce in 1827 . 


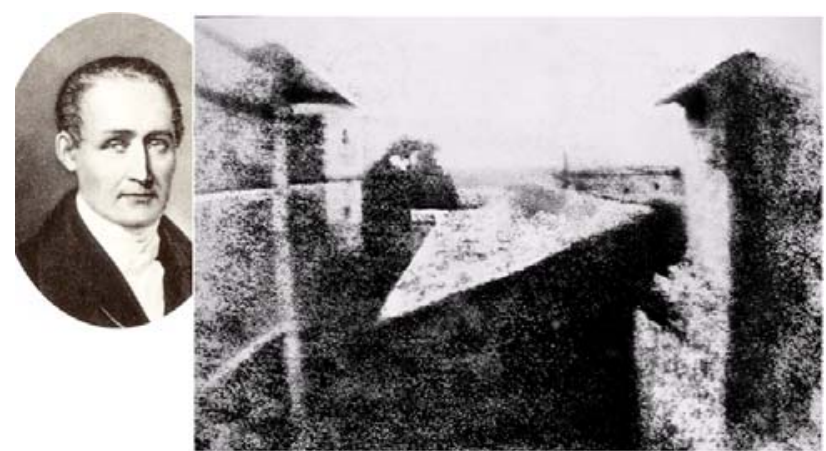

Figure 10. The well known 1st handed down photography (from approx. 1827) showing the pigeon roof through the window of the house of Joseph Nicéphore Niépce, the inventor of photography in Saint-Loup-de-Varenne (France), retouched by Gernsheim (1952), a fragment like the today's lasered crystals (of, e.g., Figure 1 to 3, 6 to 7, 10 and 12) ? (Repro by W. Schuhr)

Lasered crystals already became part of our daily life and might mark the first step of an expected booming progress in advanced 3D Visualization (not only) in the field of Cultural Heritage.

Typical technical data for laser engraving devices are:

- Maximum volume of glass bodies: $2.2 \mathrm{~m}$ x $3.2 \mathrm{~m}$ x $0.2 \mathrm{~m}$

- typical crystal body size: 50 x 50 x $80 \mathrm{~mm}$

- object size/duration: 225.000 points/ 1 to 3 minutes

- point size: $50 \mu \mathrm{m}$

- repeating accuracy in $\mathrm{x}$ and $\mathrm{y}: \pm 5 \mu \mathrm{m}$

- drive: step motor or linear motor (x, y), servomotor (z)

To stimulate the crystal structure no forward intersection of 2 laser beams is necessary, but the point by point lasering of the crystal is verified by using just one laser beam with controlled changing of focus.

A crystal, once lasered, later on still allows to continue or to add lasered objects. But to delete lasered information in crystal currently is not possible, but a matter of international research. A crystal, which allows repeated lasering and deleting of 3D information of course would be an extremely important tool, yes, even a "philosopher's stone" of a new 3D screen generation.

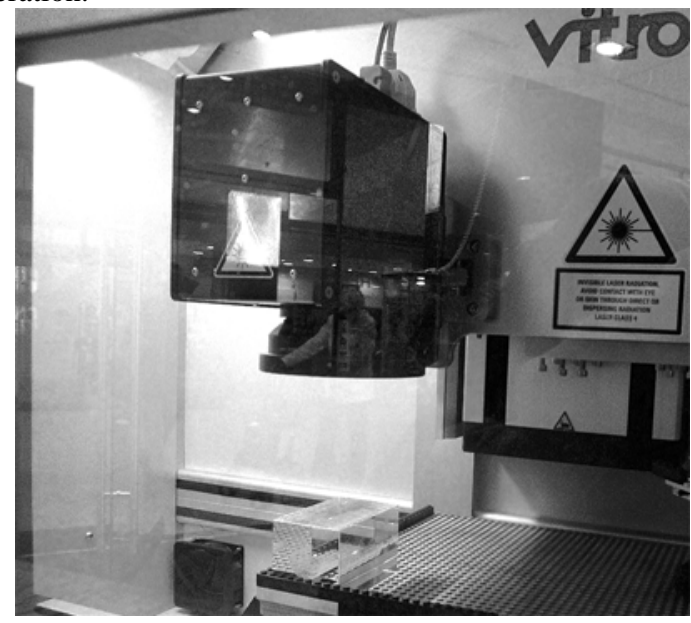

Figure 11. VITRO crystal laser engraving machine of company LOOXIS (Hannover, Germany); courtesy R.Titze (photography by W.Schuhr) (similar: CERION)
5.6 The laser crystal Technology based on Laser scanning not only deals with a new era in 3D data acquisition as well as in 3D data processing, but with high probability it also pushes a special 3D data visualization Technology, for which the current level of development remembers to the status of the invention of the photography, see Figure 10.

5.7 Furthermore lasered crystals allow a quasi freezing of moments of 3D dynamic processes like, e.g. seismic events, see Figure 12.

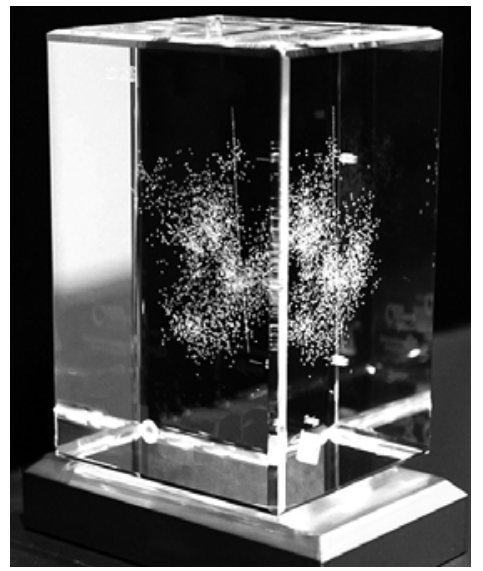

Figure 12. Sample for 3D data, relevant for cultural heritage: seismic activity preserved in crystal (courtesy by R. Titze/ comp. LOOXIS, Hannover (Germany), sample modified by Schuhr)

\section{REMARKS}

The non-commercial archive of 3D photography, running by the authors, provides and collects analog and digital 3D imagery from all over the world. If you are seeking for particular 3D photography or if you offer 3D imagery, kindly leave an email, see Figure 13.

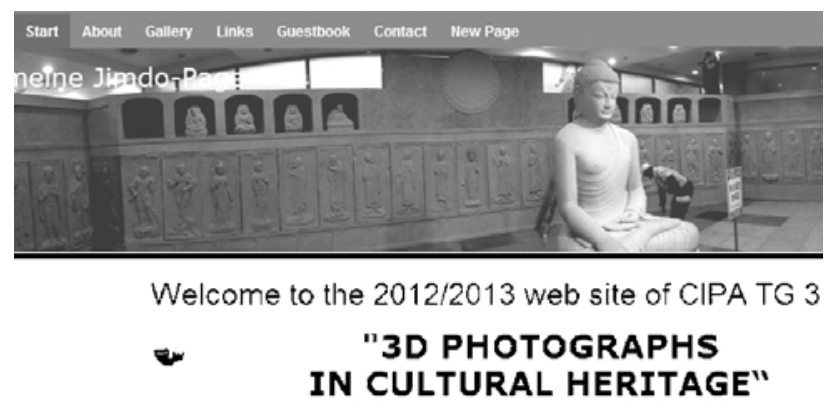

Figure 13. Panorama photography of the $1^{\text {st }}$ page of the web site www.3dphoto.jimdo.com of CIPA task group 3 on "3D photographs in Cultural Heritage” (photography by W. Schuhr). 